Article

\title{
Numerical Simulation and Experimental Validation for the Thermal Analysis of a Compact LED Recessed Downlight with Heat Sink Design
}

\author{
Huan-Chu Hsu and Yi-Cheng Huang * \\ Department of Mechatronics Engineering, National Changhua University of Education, Changhua 500, Taiwan; \\ george7519@gmail.com \\ * Correspondence: ychuang@cc.ncue.edu.tw; Tel.: +886-4-723-2105 (ext. 8138) \\ Academic Editor: Wen-Hsiang Hsieh \\ Received: 15 October 2016; Accepted: 13 December 2016; Published: 22 December 2016
}

\begin{abstract}
Light emitting diode (LED)-recessed downlighting is currently mainly used for indoor lighting of residential and commercial buildings. Maintaining a low junction temperature and increasing the lifetime and reliability of LED lighting is desirable. This study investigated designed heat sinks' heat dissipation and capability of maintaining a low junction temperature, as well as increases in the lifetime and reliability of the lighting. This paper presents a designed traditional trapezoidal aluminum finned heat sink (ALFHS) and annular open cell copper foam heat sink (CUFHS) mounted to a $10 \mathrm{~W}$ compact LED-recessed downlight (CLRDL) and individually installed in a simulation $105 \mathrm{~mm} \times 105 \mathrm{~mm} \times 100 \mathrm{~mm}(L \times W \times H)$ test box. The purpose was to evaluate the temperature performance by testing the downlight in a small enclosed space with high ambient temperature while the LED is in operation. The downlight exhibited a long lifetime at normal use temperature and functioned according to Arrhenius' law. Numerical simulation was performed first and followed by experimental validation. The heat sink design was the main factor in the heat management of the CLRDL. The heat sinks height was determined using numerical simulation and experimental validation before and after installation (INST) of the ALFHS and CUFHS. The CUFHS height was initially selected based on a larger heat dissipation capacity, and then by determining the ALFHS height. Both the ALFHS and CUFHS with the same height of $17 \mathrm{~mm}$ exhibited a similar capacity of heat dissipation before INST. Subsequent to INST, the temperature of the solder point of the ALFHS was higher than that of the CUFHS with an identical height of $17 \mathrm{~mm}$. To compare the heat dissipation behavior of the two heat sinks, the ALFHS height was increased to $23 \mathrm{~mm}$, which is $6 \mathrm{~mm}$ higher than that of the CUFHS. The results of a stationary simulation study for junction temperature coincides with the experimental results tested obtained using J-type thermocouples and a data acquisition system. The temperature of the solder point of the CLRDL with both the ALFHS and CUFHS was $91.7^{\circ} \mathrm{C}$ after INST, corresponding to an LED junction temperature of $121.7^{\circ} \mathrm{C}$, which is lower than specified $135^{\circ} \mathrm{C}$ LED limit temperature. The temperature distributions of specified points under natural convection were evaluated. The CLRDL installed in a small enclosed space withstood the lifetime requirements according to the results of an accelerated life test prediction. The CLRDL lumen maintenance was tested to be more than $25,000 \mathrm{~h}$. The experimental results demonstrate compliance with the Energy Star ${ }^{\circledR}$ requirements for indoor LED lighting fixtures.
\end{abstract}

Keywords: compact LED recessed downlight; multiphysics numerical simulation; heat sink

\section{Introduction}

In recent years, light emitting diode (LED) technology has undergone rapid growth. LED technology has become standard for both residential and commercial lighting because of its well-known 
advantages, such as long lifetime, energy saving, ecologically friendly, durable quality, design flexibility, and more controllable, instant lighting, low voltage, high luminous efficacy, high color rendering, operational in cold or hot temperatures. LED downlights are commonly used for indoor lighting. Compact LED recessed downlights (CLRDLs) provide visual comfort and efficiency, as well as being economical and eco-friendly. The shallow recess depth enables them to be used where ceiling space is limited.

Insufficient heat dissipation caused by poor ventilation, high ambient temperatures, and the thermal resistance $\left(R_{\mathrm{th}}\right)$ resulting from the long distance from LED junctions to the outside atmosphere prompted this research [1]. Cooling is crucial [2] to ensure LED lighting lifetime and performance. Maintaining a lower LED junction temperature $\left(T_{j}\right)$ tends to increase light output and slow LED lumen depreciation, ensuring reliability. Junction temperature is used to evaluate LED lighting quality and lifetime expectancy. The US EPA Energy Star ${ }^{\circledR}$ Manufacturer's Guide requires an L70 of 25,000 h for indoor lighting fixtures. L70 is defined as $70 \%$ of the initial lumen output. Thermal resistance, which is the reciprocal of thermal conductance, describes a material's resistance to heat flow and is measured in degrees Celsius per watt (equivalent to Kelvins per watt).

Heat sinks are typically used for cooling electronic devices. Two types of high-performance heat sinks, namely the aluminum finned heat sink (ALFHS) and copper foam heat sink (CUFHS), were used in this study. To determine the appropriate height of the heat sinks, the ALFHS and CUFHS were individually mounted in a CLRDL aluminum housing before and after installation (INST) for simulation and testing. Computational fluid dynamics (CFD) simulation facilitates the optimal design of heat sinks [3,4]. Regarding cost reduction, a trapezoidal fin profile is considered to be a favorable choice for replacement of the traditional rectangular fin [5]. Traditional trapezoidal fins are widely used for cooling electronic devices, and exhibit the lowest thermal resistance and maximum heat transfer coefficient [6]. Metal foam is already used in LED systems because highly porous materials have physical and mechanical advantages regarding buoyancy driven flow $[7,8]$. According to Newton's law of cooling, the heat transfer rate can be enhanced by either increasing the heat transfer coefficient or the heat transfer area under a specific temperature difference [9]. Fins are used to increase the surface-to-volume ratio of contemporary heat sinks. These fin shapes can be quite complex. A promising material that can be used for three-dimensional surface extensions is a highly porous open-cell metal foam. Open-cell metal foam is a porous medium that has a very high volumetric porosity [10]. CUFHSs achieve heat transfer through their large surface-area-to-volume ratio, tortuous flow path, low specific weight, and relatively high thermal conductivity $[11,12]$. The thermal performance of CUFHSs is 35\%-40\% higher than that of conventional aluminum metal heat sinks under a conventional comparison approach [13]. Compared with the ALFHSs, the area for heat dissipation in CUFHSs is enlarged. The parameters for heat sink design, such as the fluid flow resistance and surface-to-volume ratio, should be considered. In certain cases, some parameters may be interactive. Heuristically, enlarging heat dissipation surfaces can reduce the dissipation capability. Nevertheless, the fluid flow resistance may be affected by the total volume being limited, producing an ineffective heat escape pathway for the heat sink that results in increased heat localization. Because this study aimed to create devices with a high capacity for heat dissipation, various types of ALFHS and CUFHS using different materials were examined. Although they have fundamental differences, this study used ALFHSs and CUFHSs to develop optimal heat sinks with high dissipation capacities.

LED lifetime is subject to junction temperature. Lower junction temperatures tend to produce longer lifetimes. Therefore, LED cooling is necessary. Heat sinks have an important role in the natural convection cooling of LED lighting. Selecting suitable materials and determining appropriate dimensions are the main factors. In this study, the dimensions were determined by simulating the different height of the materials. The CUFHS height was determined first, followed by the ALFHS height. Of $5 \mathrm{~mm}, 10 \mathrm{~mm}$, and $17 \mathrm{~mm}$ height copper foam materials, the $17 \mathrm{~mm}$ material was selected because of its higher heat dissipation capacity. Simulation and testing were then conducted before and after INST. ALFHSs with heights of $16 \mathrm{~mm}, 20 \mathrm{~mm}$, and $23 \mathrm{~mm}$ were simulated and tested to 
compare them with the $17 \mathrm{~mm}$ CUFHS. To compare the heat dissipation behavior with both heat sinks, the $23 \mathrm{~mm}$ ALFHS was then examined. Finally, the $23 \mathrm{~mm}$ ALFHS and $17 \mathrm{~mm}$ CUFHS were selected.

A comparison of the temperature of the solder point $\left(T_{\mathrm{sp}}\right)$ for the ALFHS and CUFHS before and after INST is presented in Table 1. Before INST, for case 1 , the $T_{\mathrm{sp}}$ values of the ALFHS and CUFHS both with $17 \mathrm{~mm}$ height were very similar. For cases 2 and 3, the $T_{\mathrm{sp}}$ values of the 20 and $23 \mathrm{~mm}$ height CUFHS were higher than those of the ALFHS by $1.6^{\circ} \mathrm{C}$ and $3.2^{\circ} \mathrm{C}$, respectively. After INST, for cases 1 and 2, the $T_{\mathrm{sp}}$ values of the ALFHS were higher than those of the CUFHS by $8.4^{\circ} \mathrm{C}$ and $2.8^{\circ} \mathrm{C}$, respectively. For case 3 , the same $T_{\mathrm{sp}}$ was obtained for both the ALFHS and CUFHS.

These results indicate that (1) The $17 \mathrm{~mm}$ height ALFHS and CUFHS exhibited a very similar capacity for heat dissipation before INST. The high conductivity of the copper foam material compensates for its higher fluid flow resistance caused by its increased pressure drop; (2) For the same height, the ALFHS $T_{\mathrm{sp}}$ was higher than that of the CUFHS after INST because the heat dissipation concentrated centrally above the heat sink with higher velocity. Unlike in the ALFHS, the heat accumulated along the heat sink to the cover of the test box, resulting in less efficient transfer of heat from inside the ambient of the test box to the outside atmosphere. The copper foam can potentially increase the heat transfer rates from solid surfaces by conducting heat to the material struts and inducing a high interaction between the struts and a through-flowing fluid [11]; and (3) After INST, the same $T_{\mathrm{sp}}$ was obtained for the ALFHS and CUFHS by increasing the height of the ALFHS to $23 \mathrm{~mm}$, which was $6 \mathrm{~mm}$ higher than that of the CUFHS, thereby increasing the efficiency of fin performance. This facilitated comparing the heat dissipation behavior of the heat sinks. The $T_{\mathrm{sp}}$ of both heat sinks was $91.7^{\circ} \mathrm{C}$, which is a suitable heat dissipation capacity for the purpose of this study.

Table 1. Comparison for heat sinks height determination.

\begin{tabular}{|c|c|c|c|c|c|c|c|c|}
\hline \multirow[b]{2}{*}{ Case } & \multirow{2}{*}{$\begin{array}{l}\text { Heat } \\
\text { sink }\end{array}$} & \multirow{2}{*}{$\begin{array}{l}\text { Height } \\
\text { (mm) }\end{array}$} & \multicolumn{3}{|c|}{ Before } & \multicolumn{3}{|c|}{ After } \\
\hline & & & \multirow{2}{*}{$\frac{T_{\mathrm{sp}}\left({ }^{\circ} \mathrm{C}\right)}{87.0}$} & \multicolumn{2}{|c|}{$\begin{array}{c}\text { Temperature } \\
\text { Difference }\left({ }^{\circ} \mathrm{C}\right)\end{array}$} & \multirow{2}{*}{$\frac{T_{\text {sp }}\left({ }^{\circ} \mathbf{C}\right)}{100.1}$} & \multicolumn{2}{|c|}{$\begin{array}{c}\text { Temperature } \\
\text { Difference }\left({ }^{\circ} \mathrm{C}\right)\end{array}$} \\
\hline \multirow{2}{*}{1} & ALFHS & 17 & & Higher & 0.4 & & Higher & 8.4 \\
\hline & CUFHS & 17 & 86.6 & & & 91.7 & & \\
\hline \multirow{2}{*}{2} & ALFHS & 20 & 85.0 & & & 94.5 & Higher & 2.8 \\
\hline & CUFHS & 17 & 86.6 & Higher & 1.6 & 91.7 & & \\
\hline \multirow{2}{*}{3} & ALFHS & 23 & 83.4 & & & 91.7 & & \\
\hline & CUFHS & 17 & 86.6 & Higher & 3.2 & 91.7 & Same & 0.0 \\
\hline
\end{tabular}

The simulated $T_{\mathrm{sp}}$ values for ALFHSs with heights of $16 \mathrm{~mm}, 20 \mathrm{~mm}$, and $23 \mathrm{~mm}$ were $104.0^{\circ} \mathrm{C}$, $95.7^{\circ} \mathrm{C}$, and $91.7^{\circ} \mathrm{C}$, respectively. The $23 \mathrm{~mm}$ heights ALFHS was then used in this study because of its higher heat dissipation capacity and its heights being acceptable for CLRDL design.

Figure 1 illustrates the length of the thermal dissipation path around the LED junction, solder point, metal core printed circuit board (MCPCB), aluminum housing, heat sink (ALFHS or CUFHS), and test box (plywood, $13 \mathrm{~mm}$ thick, $105 \mathrm{~mm} \times 105 \mathrm{~mm} \times 100 \mathrm{~mm}, L \times W \times H$ ) to the atmosphere. Another path involved dissipation from the aluminum housing, through the trim (a decorated flange of CLRDL exposed below the ceiling) to the atmosphere. Such thermal path media travel from the heat sink through the test box to the atmosphere via the air and plywood. However, the thermal conductivities of air and plywood are $0.024 \mathrm{~W} / \mathrm{m} \cdot \mathrm{K}$ and $0.13 \mathrm{~W} / \mathrm{m} \cdot \mathrm{K}$ at $25{ }^{\circ} \mathrm{C}$. This causes high temperatures inside the test box, and increased junction temperatures. This study used this high temperature mechanism to verify the heat sink performance. The thermal resistance findings are illustrated in Figure 2. 


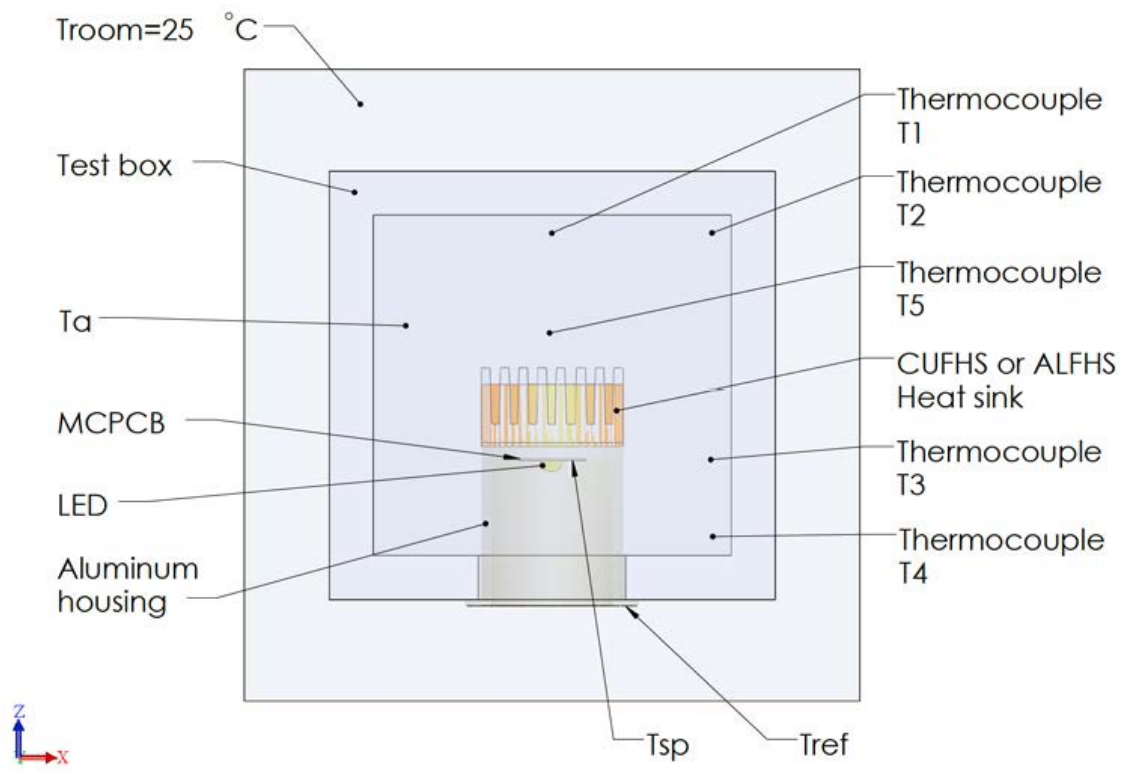

Figure 1. Illustration of the ALFHS or CUFHS mounted to the CLRDL after INST.

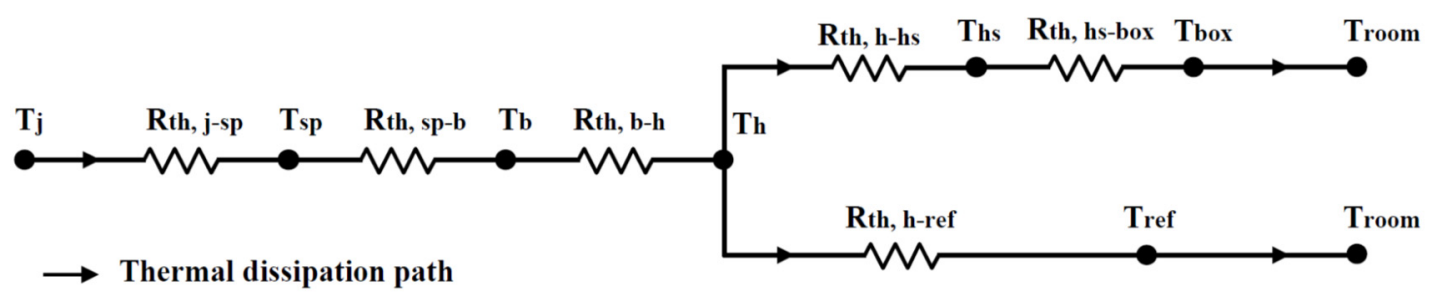

Figure 2. Illustration of thermal resistance network for the CLRDL after INST.

Effective cooling is particularly necessary in recessed fixtures, where ceiling insulation can obstruct the heat escape paths. The challenge, which can be addressed in different ways by numerous design strategies, is to maximize the capacity for heat to escape from the fixture for a given LED operating temperature. In this study, the thermal behavior of partially-recessed style lighting was modeled and measured in a configuration for a CLRDR. The thermal performance of the recessed fixtures was evaluated experimentally in a wooden box (i.e., the test box). The test box was used to emulate an insulated ceiling for testing purposes as in [14].

Light emission does not account for all power consumption. In high-power LEDs, approximately $25 \%$ of input power is converted to light. The rest is dissipated in the form of heat, causing the light extraction efficiency, emission intensity, and lifetime to decrease [15]. Poor thermal management may cause LEDs to fail in a few months, resulting in high LED junction temperatures [16]. Since high power LEDs are widely used in lighting fixtures, designing suitable heat sinks for maintaining a low LED junction temperature is particularly necessary. Temperature modeling according to the Arrhenius equation (Equation (1)) is widely used for reliability validation. This study examined CLRDLs by using an ALFHS and CUFHS installed in a small test box. While an LED is in operation, the temperature rises rapidly because of the heat generation from the P-N junction. The inner temperature of the test box was rapidly increased from the LED during the initial $2 \mathrm{~h}$. The buoyancy flow results from density variations caused by temperature changes in different areas of the test box. This phenomenon can be observed both the numerical temperature distribution simulation and experimental results. In the test conditions, the LED junction temperature increase was markedly higher than it was in normal use conditions. The accelerated life test [17] was applied here to predict the CLRDL lifetime with accelerated ambient temperature was $55^{\circ} \mathrm{C}$. 
The Arrhenius equation predicts device lifetimes by modeling the relation between the increased temperature (temperature in testing) and the acceleration of the aging of a device as compared with its normal operational temperature (temperature in normal use).

$$
\text { A.F. }=\exp \left[\frac{E a}{k}\left(\frac{1}{T_{\text {use }}}-\frac{1}{T_{\text {test }}}\right)\right]
$$

\section{Problem Formulation}

This paper reports on two heat sinks that were intended for $10 \mathrm{~W}$ CLRDL cooling. The ALFHS had a $23 \mathrm{~mm}$ height. The CUFHS had a $17 \mathrm{~mm}$ height and consisted of the open cell soldered on a thin copper plate by using solder paste. It was a copper foam with 40 PPI and featured a porosity $\left(\varepsilon_{\mathrm{p}}\right)$ of 0.90 [4]. Both heat sinks were individually mounted to an aluminum housing. The tested CLRDL was installed inside the test box through a pre-opened hole in the center of the bottom wall of the test box. This design goal was to evaluate both the ALFHS and CUFHS to determine whether the target heat dissipation capacity was achieved.

An isometric illustration of the study set-up is shown in Figure 3. Figure 3a shows the ALFHS or CUFHS mounted to the CLRDL and installed in the test box. As depicted, both heat sinks were mounted above the aluminum housing. Figure $3 \mathrm{~b}$, provides the bottom view of the LED, MCPCB, and the specified test points $T_{\mathrm{sp}}$ and reference temperature $\left(T_{\text {ref }}\right)$ for the CLRDL. In both illustrations, the $T_{\mathrm{a}}$ and $T_{\text {room }}$ were different because of the $T_{\mathrm{a}}$ being in the enclosed area, and the $T_{\text {room }}$ in free atmosphere.

To verify our design, some specified temperature points were measured, as shown in Figures 1a,b and $3 \mathrm{~b}$. The specified test points were $T_{\mathrm{sp}}, T_{\text {ref }}, T_{1}, T_{2}, T_{3}, T_{4}$, and $T_{5}$. Since the junction temperature cannot be measured directly, it was calculated using Equation (2). The $T_{\mathrm{sp}}$ measured using a J-type thermocouple that was connected to the data acquisition system to generate the temperature profiles. $T_{\text {ref }}$ was used for calibration of the numerical simulation and experiments. The correlation between $T_{\text {ref }}$ and $T_{\text {sp }}$ provided the referenced temperature difference.

In Equation (2), the coefficient of the thermal resistance $R_{\mathrm{j}-\mathrm{sp}}$ between the $T_{\mathrm{j}}$ and the LED $T_{\mathrm{sp}}$ was experimentally determined and was approximated at $3.0 \mathrm{~K} / \mathrm{W}$ for a MCPCB (see the LED datasheet). The junction temperature was calculated as follows:

$$
T_{\mathrm{j}}=T_{\mathrm{sp}}+T_{\mathrm{th}, \mathrm{j}-\mathrm{sp}} \cdot P_{\mathrm{total}}
$$

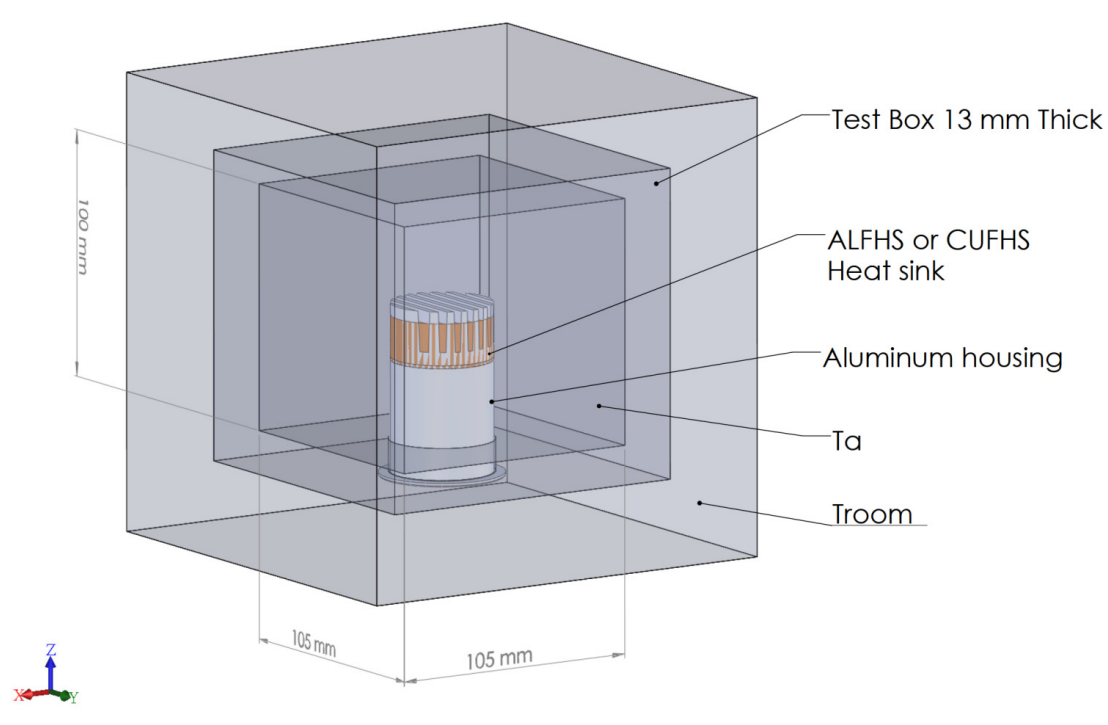

(a)

Figure 3. Cont. 


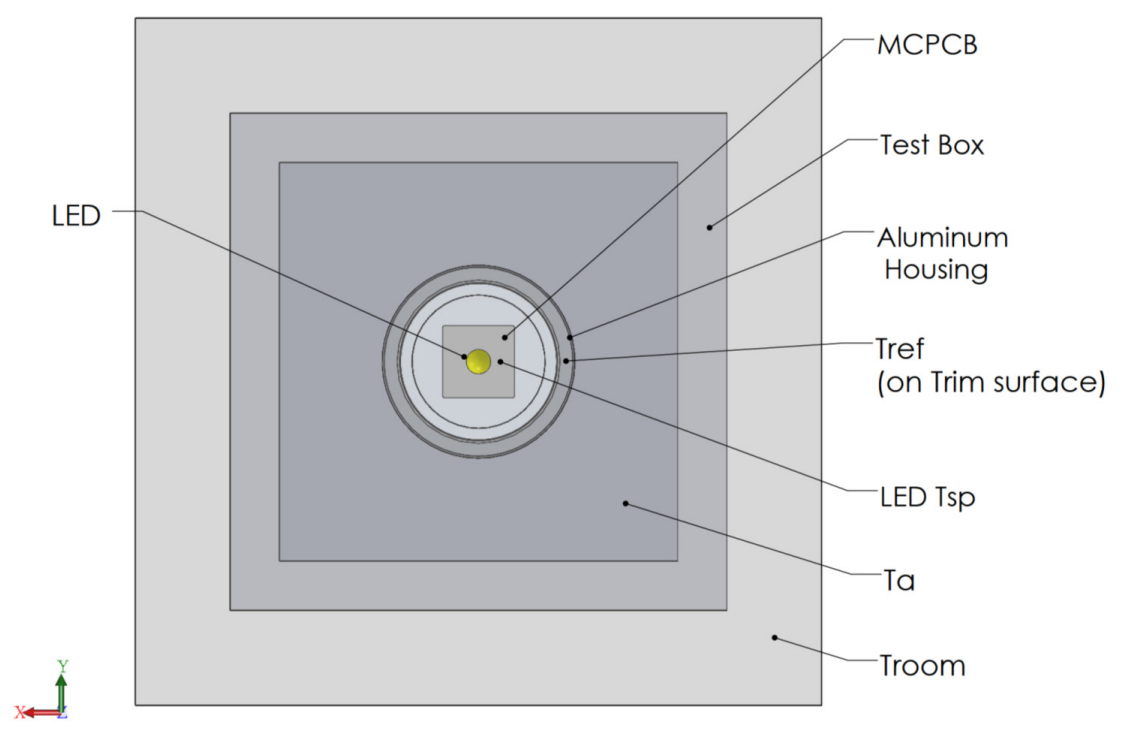

(b)

Figure 3. Illustration of the (a) isometric view of the ALFHS or CUFHS mounted to the CLRDL after INST; and (b) bottom view of LED, MCPCB, trim and the test point of $T_{\mathrm{sp}}, T_{\text {ref }}$.

\subsection{Theoretical Background}

For the ALFHS, the first set of governing equations for the conjugate heat transfer in CLRDLs in non-isothermal flow air models was formulated as follows $[18,19]$.

The momentum equation of non-isothermal flow:

$$
\rho(u \cdot \nabla u)=\nabla \cdot\left[-p I+\mu\left(\nabla u+(\nabla u)^{T}\right)-\frac{2}{3} \mu(\nabla \cdot u) I\right]+F
$$

The left-hand side of the equation represents the inertial forces. The first term on the right-hand side is the pressure force, the second term is the viscous force, and the third term is the external force applied on the fluid.

For air mass continuity, we have:

$$
\nabla \cdot(\rho u)=0
$$

Convective and conductive heat transfer is governed by:

$$
\rho C_{p} u \times \nabla T=\nabla \cdot(-k \nabla T)+Q
$$

The volume force is:

$$
F=-\rho g
$$

The second set of governing equations for the CUFHS coupled with free and porous media flow and heat transfer in porous media models is explained as follows. The Navier-Stokes and Brinkmann equations for laminar flow are used for coupling the flow in porous media models. The Navier-Stokes equation is for flow in free flow regions and the Brinkman extension is for flow in porous regions.

The governing equations for free flowing fluids are as follows:

$$
\begin{gathered}
\left.\rho(u \times \nabla) u=\nabla \cdot\left[-p I+\mu(\nabla u)+(\nabla u)^{T}\right)\right]+F \\
\rho \nabla \cdot u=0
\end{gathered}
$$

The equations for free and porous media flow are as follows. 
The momentum equation is:

$$
\frac{\rho}{\varepsilon_{\mathrm{p}}}\left((\mathrm{u} \cdot \nabla) \frac{\mathrm{u}}{\varepsilon_{\mathrm{p}}}\right)=\nabla \cdot\left[-p I+\frac{\mu}{\varepsilon_{\mathrm{p}}}\left(\nabla u+(\nabla u)^{T}\right)-\frac{2 \mu}{3 \varepsilon_{\mathrm{p}}}(\nabla \cdot u) I\right]-\left(\mu \mathrm{K}^{-1}+\beta_{F}|u|+\frac{\mathrm{Q}_{\mathrm{br}}}{\varepsilon_{\mathrm{p}}^{2}}\right) u+F
$$

The continuity equation is:

$$
\rho \nabla \cdot u=Q_{\mathrm{br}}
$$

The equation for heat transfer in porous media is:

$$
\rho C_{\mathrm{p}} u \times \nabla T=\nabla \cdot\left(K_{\mathrm{eff}} \nabla T\right)+Q
$$

The Boussinesq buoyancy approximation is commonly used in natural convection. The Boussinesq term is then used as the volume force F on the right-hand side of Equation (9):

$$
F=\rho g \beta\left(T-\mathrm{T}_{0}\right)
$$

\subsection{Numerical Simulation Modeling}

The thermal characteristics of LED lighting devices have been studied using finite element method (FEM) simulation tools. However, numerous FEM tools could be equally effective in thermal simulations $[20,21]$. This study involved performing numerical simulation by using COMSOL Multiphysics software (COMSOL, Inc., Burlington, MA, USA) [18] to analyze CLRDL thermal management [22].

The simulation module included the predefined non-isothermal flow model of Multiphysics coupled to simulated systems for density variations with temperature. The "conjugate heat transfer in non-isothermal flow" model from COMSOL Multiphysics was used for the ALFHS mounted in the CLRDL, and the coupled "free and porous media flow and heat transfer in porous media" model was used for the CUFHS mounted in the CLRDL. The stationary models involving steady-state "free fluid and solid coupling with heat", and "free and porous media flow coupling with heat", as well as general heat transfer models were set up for the simulation.

Heat transfer in natural convection was applied according to the conditions of commercially available CLRDLs. Passive methods that use natural convection are generally characterized by high reliability $[23,24]$. Natural convection is widely implemented in the lighting industry because of its low cost, low noise, simplicity, small size, and reduction of reliability issues [18] caused by active convection part failure. Heat sinks that employ natural convection require no additional power supply. Additionally, they are almost maintenance free, which is suitable for long lifetime devices, such as LEDs [25].

However, the use of heat dissipation through natural convection heat transfer introduces the problem of low heat reduction efficiency. Air flow velocity is quite slow, especially in enclosed areas. Thus, relying on conducting repeated experiments is inadequate for meeting the design requirements for an effective, high-quality heat sink. For natural convection, a high volume of space is essential because larger spaces lead to high air velocity. To investigate the relations between space and the natural convection around solid state lighting systems, simulations with various dimensions of typical enclosures [26] were performed. Numerical simulation software facilitates enhancing the heat management design performance [27].

We applied the specified models for the ALFHS and CUFHS mounted to the CLRDL and installed in the test box individually. The models were applied to conditions in which the high temperature in the test box is reached in a steady state. Designing heat sinks with heat dissipation capabilities that satisfy the condition that the LED junction temperature remains below a specified temperature is imperative. 


\subsection{Experimental Fabrication}

The fabricated ALFHS and CUFHS are shown in Figure 4a,b, respectively. The round ALFHS is composed of aluminum and the round CUFHS is composed of 40 PPI copper foam, with the copper foam joined to the copper plate by solder paste.

Figure 3a depicts the test box which is constructed of $13 \mathrm{~mm}$ thick plywood with dimensions of $105 \mathrm{~mm} \times 105 \mathrm{~mm} \times 100 \mathrm{~mm}(L \times W \times H)$. The lighting output area is shown in Figure 3b. Both of the heat sinks were mounted to the same CLRDL that was assembled in the test box. Figure 5 is a photo of the experimental set-up for the CLRDL.

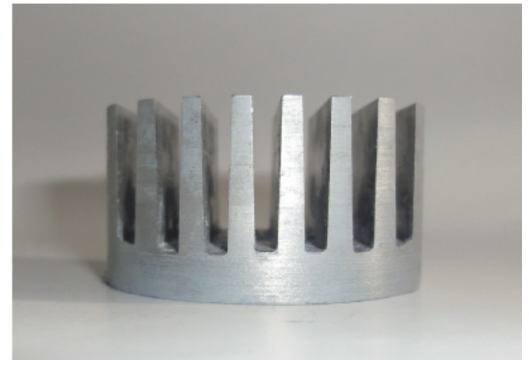

(a)

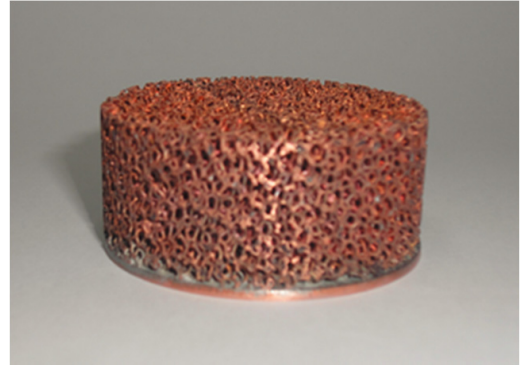

(b)

Figure 4. Two photos of heat sinks; (a) ALFHS and (b) CUFHS.

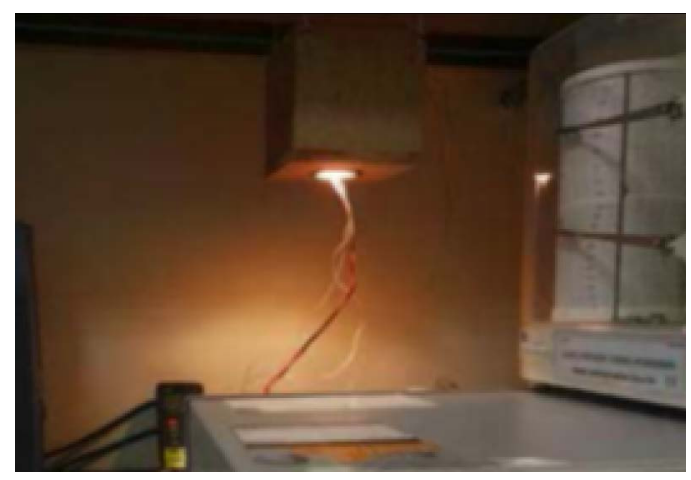

Figure 5. Photo of the experimental setup for the ALFHS or the CUFHS mounted to the CLRDL after INST.

\section{Results and Discussion}

\subsection{Numerical Simulations Results}

Figure $6 \mathrm{a}, \mathrm{b}$ depict the numerical simulation of the temperature and velocity distribution of the CLRDL with the ALFHS and CUFHS mounted devices. This figure confirms that natural or free convection is caused by density differences because of the buoyancy induced by the velocity flow pattern. Comparing Figure 6a,b reveals that hot air rises faster in the ALFHS. Heat sink circulation concentrates the air flow centrally at the inside top of the test box; the air then diffuses along the surface below the top cover of the test box. Due to the buoyancy force, the top area and the area around the testing downlight had a high temperature; areas close to the plywood wall and in the lower position had a lower temperature. For the CUFHS, in Figure $6 \mathrm{~b}$, the air flow based on the heat sink circulation is similar to that of the ALFHS, except for a difference in the hot air flow behavior. Figure $6 \mathrm{~b}$ indicates that the CUFHS provides an enlarged hot air diffusion region around the testing downlight. The different heat dissipation orientations and affected areas for heat transfer and convection of the designed ALFHS and CUFHS are displayed. 
The flow velocity of the ALFHS was $0.14 \mathrm{~m} / \mathrm{s}$. The velocity of the CUFHS was $0.01 \mathrm{~m} / \mathrm{s}$ lower than that of the ALFHS. The velocity of the CUFHS was slower than that of the ALFHS. This resulted in hot air rising at low speeds. Nevertheless, because the porous medium of the CUFHS had a large area-to-volume ratio, the contribution of heat dissipation was greater along all of the porous medium surfaces. The results show that the LED $T_{\mathrm{sp}}$ values of the CLRDL with the ALFHS and CUFHS were 91.7 and $91.8^{\circ} \mathrm{C}$.

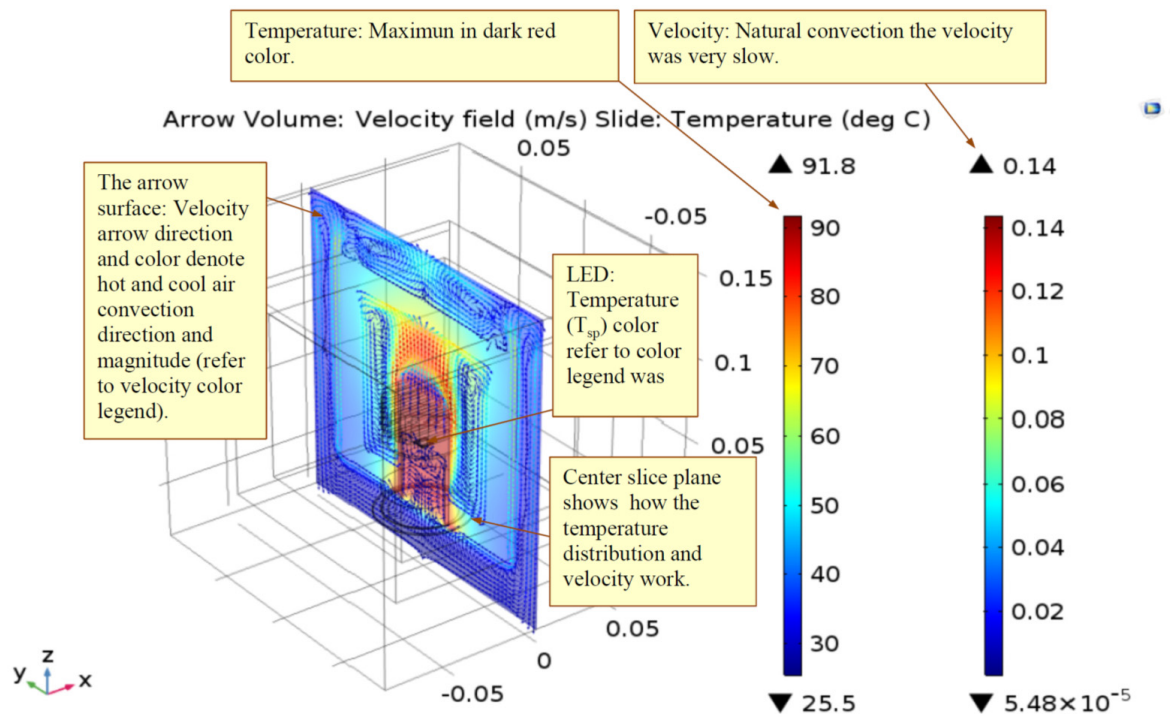

(a)

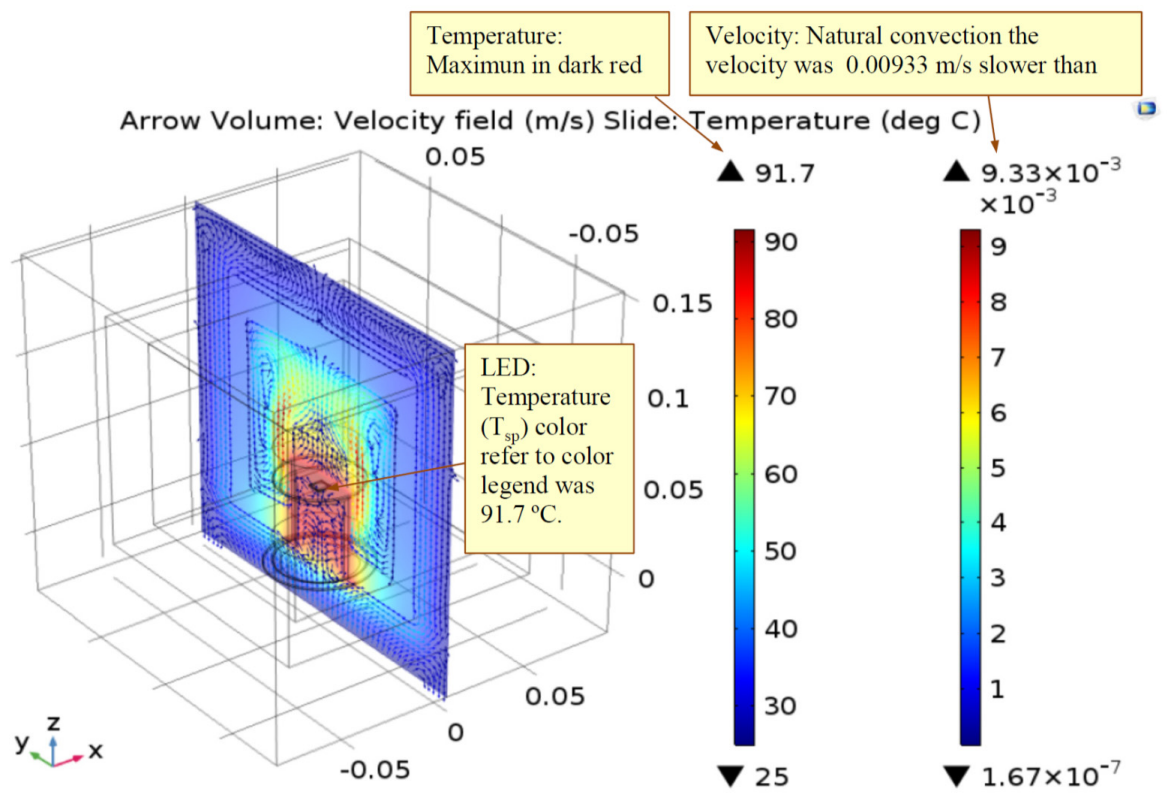

(b)

Figure 6. Illustration for the numerical simulation results of the CLRDL after INST (a) with mounted ALFHS; and (b) with mounted CUFHS.

Figure 7 presents the temperature field and fluid flow velocity field. The color slice shows the temperature field distribution. The arrow volume shows the fluid flow velocity field. The left color legend for temperature field from dark blue to dark red denotes low to high temperature. Next to the temperature legend is the color legend for arrow volume; the arrow volume color indicates the velocity field, with dark blue to dark red denoting low to high fluid velocity, respectively. The arrow indicates 
the fluid flow direction from minimum to maximum velocity in each velocity field. A consistent connection between the temperature distribution and velocity field was indicated in the numerical simulation, with the phenomenon of higher ambient temperature being accompanied by a higher velocity in the test box (Figure 7).

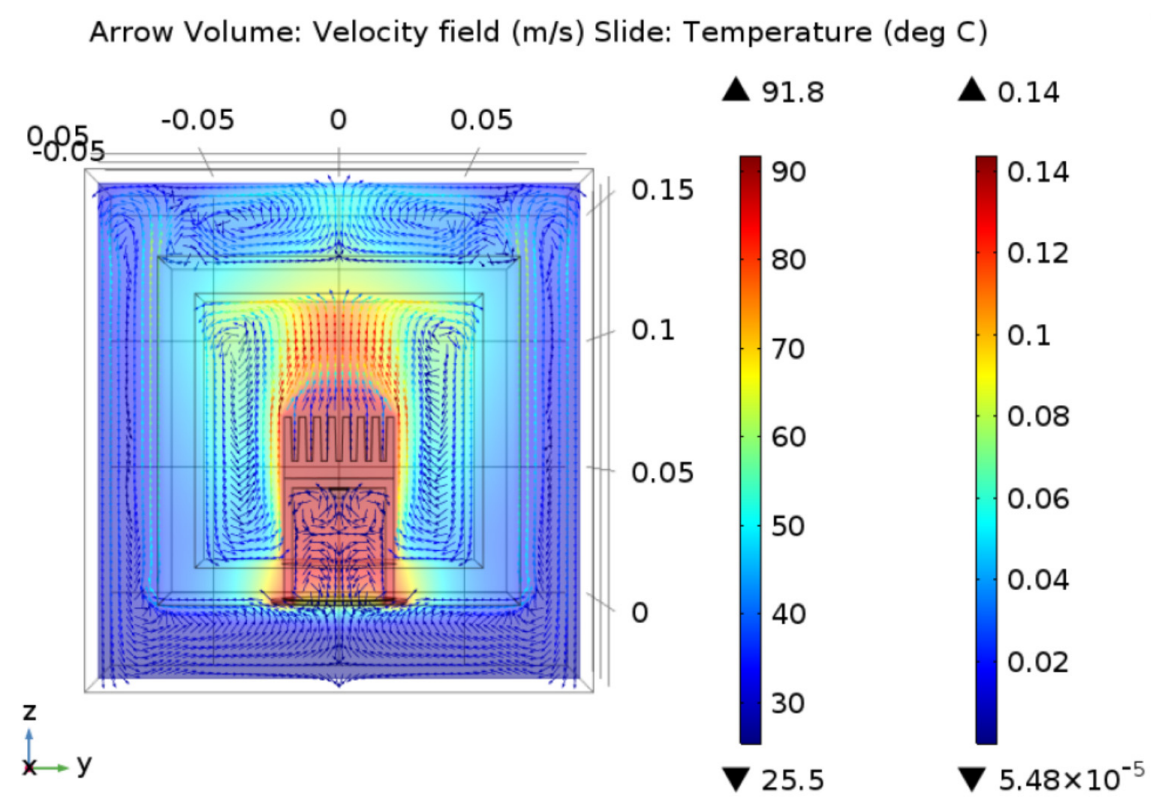

(a)

Arrow Volume: Velocity field $(\mathrm{m} / \mathrm{s})$ Slide: Temperature $(\operatorname{deg} \mathrm{C})$
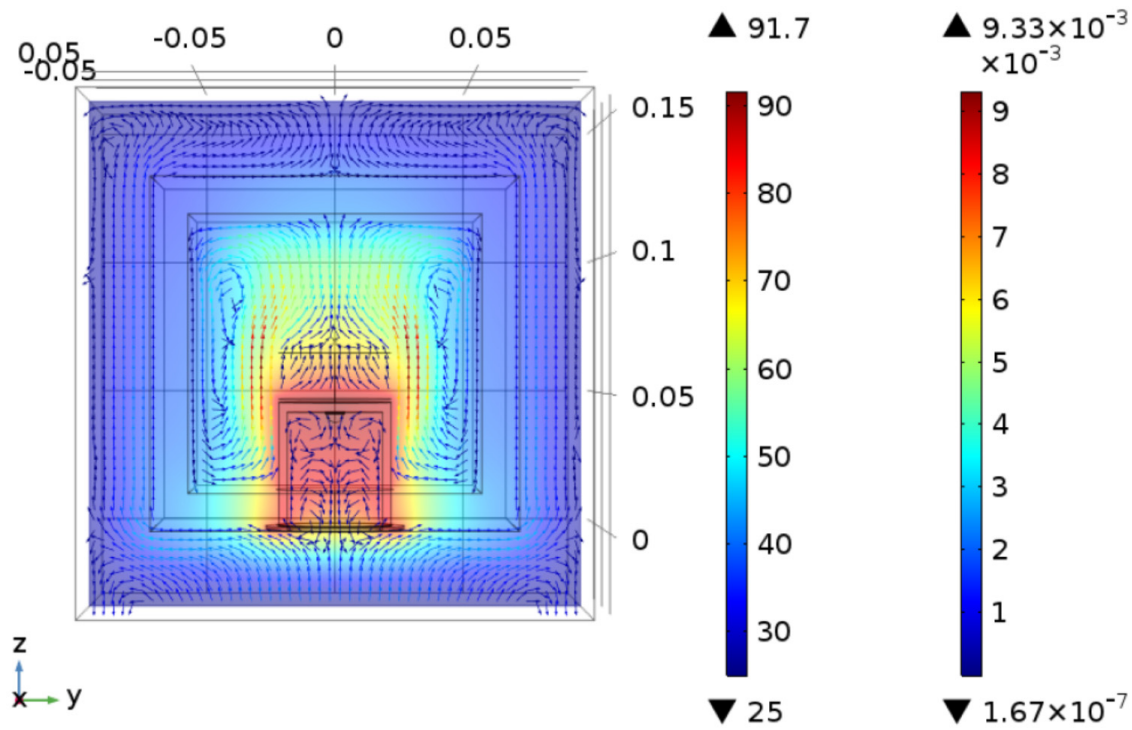

(b)

Figure 7. Simulation results of temperature and fluid flow velocity fields (view of yz plane) after INST.

(a) with mounted ALFHS; and (b) with mounted CUFHS.

As shown in Figure 8a1, at points $T_{1}$ and $T_{2}$, the area temperature was greater than $65^{\circ} \mathrm{C}\left(T_{2}\right)$, with the highest temperature in the center area $\left(T_{1}\right)$. Figure $8 \mathrm{~b} 1$ indicates the same position for the CUFHS. The temperature was much lower than is shown in Figure 8a1. As mentioned, because the porous media of the CUFHS had a large area-to-volume ratio, and larger heat-exchanger surface 
area, the contribution of heat dissipation was greater along all of the porous surfaces. Therefore, the temperature distribution shown in Figure $8 \mathrm{~b} 1$ at equivalent positions was lower than Figure 8a1. In Figure 8a2, the most marked temperature of the ALFHS is $91.8^{\circ} \mathrm{C}\left(T_{\mathrm{sp}}\right)$; however, the temperature of the point near the wall of the test box $\left(T_{3}\right)$ was much lower than the $T_{\mathrm{sp}}$. Figure $8 \mathrm{~b} 2$ shows the same position for the CUFHS: the $T_{\mathrm{sp}}$ was $91.7^{\circ} \mathrm{C}$ and $\mathrm{T}_{3}$ was similar to that shown in Figure $8 \mathrm{a} 2$ for the ALFHS. As shown in Figure 8b2, the hot air area was enlarged around the downlight itself, because the diameter is larger than that in Figure 8a2. This is because the CUFHS circulates the heat through the heat exchanging and interaction of heat conduction and natural convection, whereas the ALFHS contributes to heat exchange in a vertical direction toward the ceiling.

Figure 8a3,b3 show the temperature for the $\mathrm{T}_{4}$ point. This is the lowest position $(10 \mathrm{~mm}$ above the bottom surface inside of the test box; i.e., the point near the wall). As in Figures 6 and 7, the hot air region of Figure $8 \mathrm{~b} 3$ was enlarged around the downlight itself. The affected diameter is larger than that in Figure $8 \mathrm{a} 3$ because of the random natural convection exhibited by the CUFHS.

Regarding Figure $8 \mathrm{a} 4, \mathrm{~b} 4$, the $T_{5}$ point was the closest point above the designed heat sinks. Figure $8 \mathrm{a} 4$ indicates that the hot air circulates in the center area. The temperature of the entire horizontal plane was over $60^{\circ} \mathrm{C}$. The $T_{5}$ value shown in Figure $8 \mathrm{~b} 4$ is lower than that in Figure 8a4, because of the CUFHS height being $6 \mathrm{~mm}$ lower than that of the ALFHS. As illustrated in Figure 8a5,b5, the $T_{\text {ref }}$ for the CUFHS was similar to that of the ALFHS.

$$
\text { (a1) }
$$

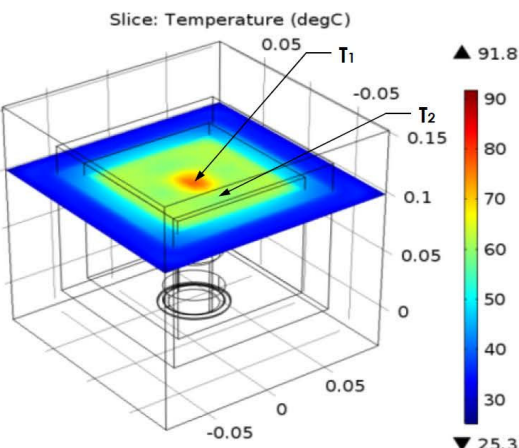

(a2)

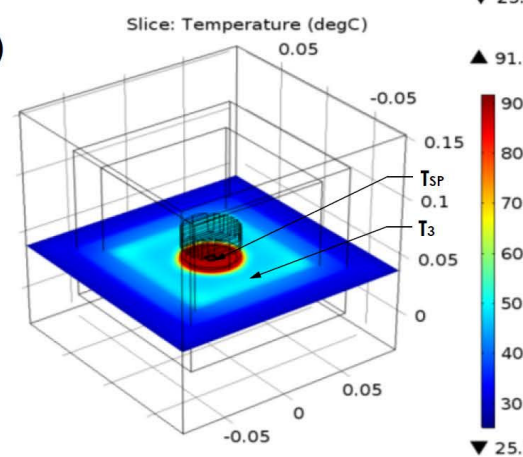

(a3)

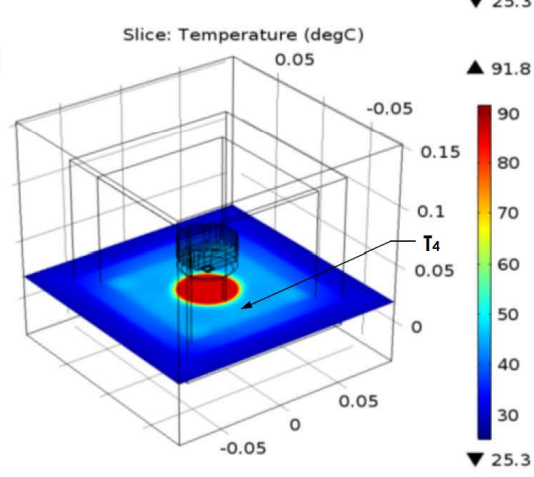

(b1)

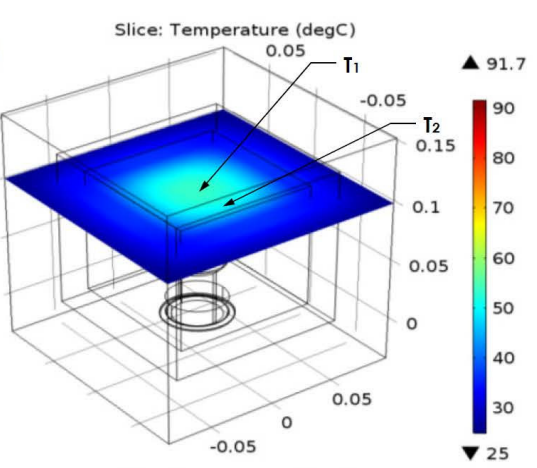

(b2)
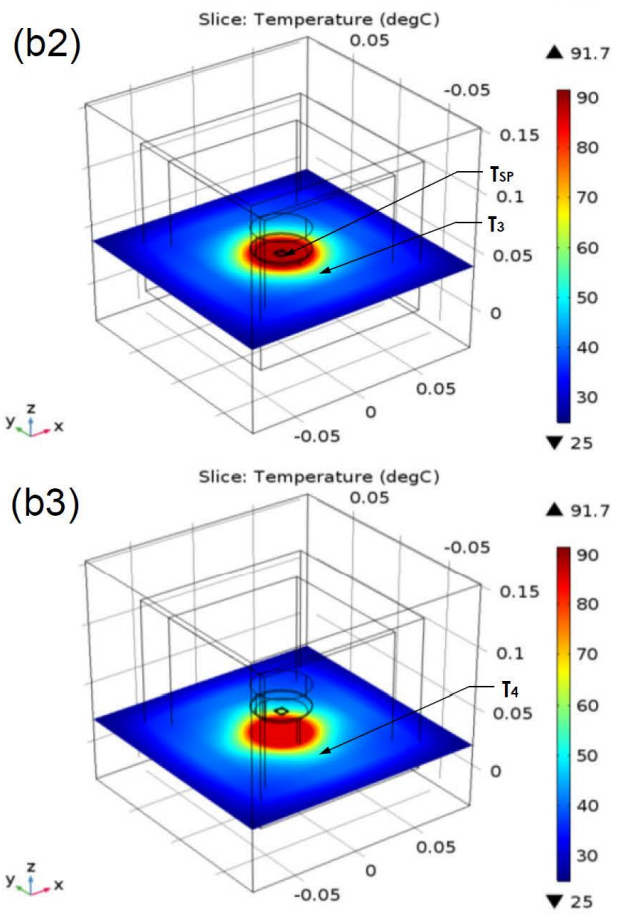

Figure 8. Cont. 
(a4)

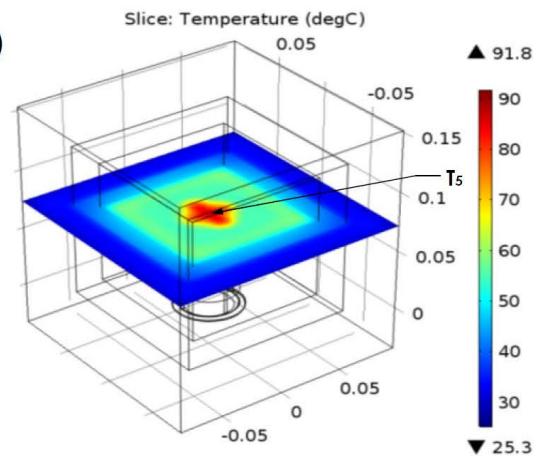

$y_{x \rightarrow x}^{2}$

(a5)

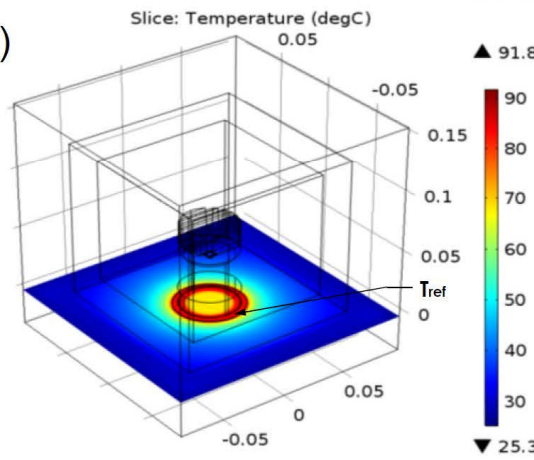

-

(b4)

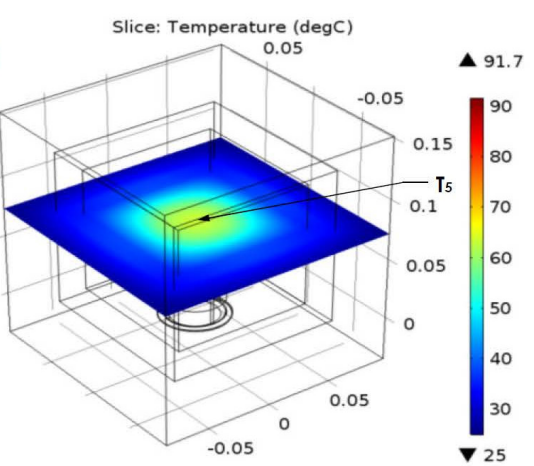

(b5)

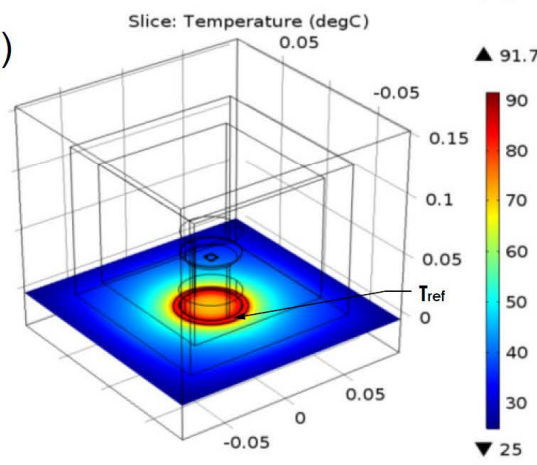

Figure 8. (a1-a5) show the simulation results using an isometric view ( $x y$ plane) for the temperature distribution at $T_{1}, T_{2}, T_{\mathrm{sp}}, T_{3}, T_{4}, T_{5}$, and $T_{\text {ref }}$ points of ALFHS; (b1-b5) are of the CUFHS; each of them are mounted to the CLRDL after INST.

\subsection{Experimental Results}

Figure 9 provides the temperature profiles of the experimental results for the temperature distribution at the $T_{\mathrm{sp}}, T_{\text {ref }}, T_{1}, T_{2}, T_{3}, T_{4}$, and $T_{5}$ points, as well as the calculation of $T_{\mathrm{j}}$ for the ALFHS mounted to the CLRDL. Figure 10 provides the profile for the CUFHS mounted to the CLRDL. The temperature distributions in the steady-state are shown in Tables 1 and 2, respectively. The experimental results show that all downlight temperature distributions differed except for the $T_{\mathrm{sp}}$ distribution.

The temperature of each specified point increased gradually; however, the temperature gradients were different. In the ALFHS and CUFHS, the $T_{\text {sp }}$ changed faster in the steady-state at $91.7^{\circ} \mathrm{C}$. The $T_{\mathrm{j}}$ was calculated as being $121.7^{\circ} \mathrm{C}$. In both cases, the $T_{\text {ref }}$ was lower than the $T_{\text {sp }}$ because of the effect of thermal resistance $\left(R_{\mathrm{th}}\right.$ sp-ref $)$. The $T_{\mathrm{a}}$ was the temperature in the enclosed test box, which varied over time at different points. The margin of error for the temperature between the numerical simulation and the experimental results was within $2 \%$.

The $T_{\mathrm{j}}$ of an LED lamp operating at any specified temperature ambience can be predicted quickly with the unique thermal resistance model by using the temperature that was measured at a reference point [28]. We can obtain the $T_{\mathrm{sp}}$ by measuring the $T_{\text {ref }}$ temperature; $T_{\mathrm{j}}$ can then be calculated using Equation (2).

The experimental results displayed in Tables 2 and 3 demonstrate that the CUFHS and ALFHS exhibited similar heat sink capability for CLRDL thermal reduction. In this study, the numerical simulation was performed first and was followed by the experimental validation for heat sinks. An industrialized test box and lighting structure design were produced and reliability predictions were conducted using an accelerated life testing. 
Temperature distributions using ALFHS
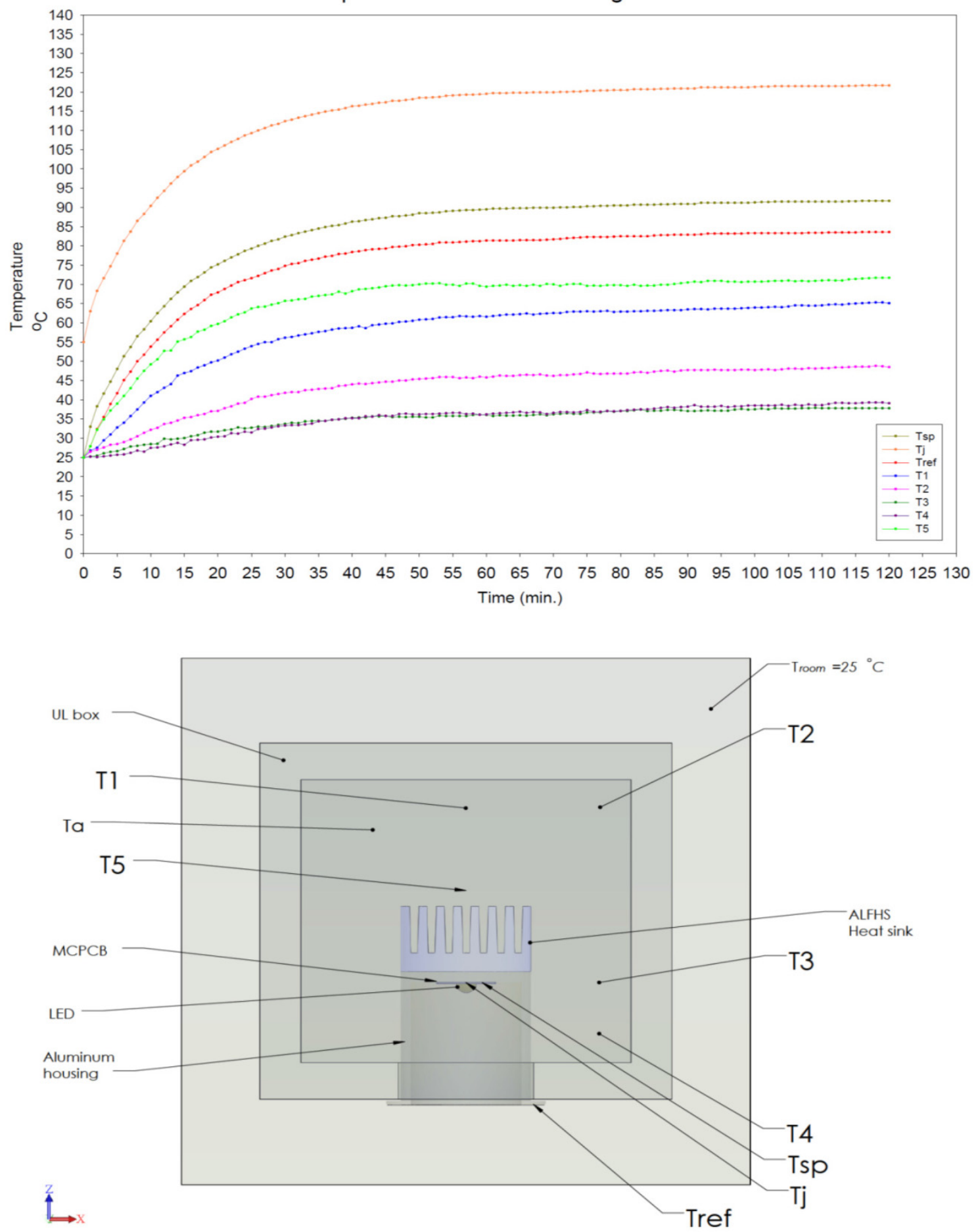

Figure 9. Chart of specified points of $T_{\mathrm{sp}}, T_{\mathrm{j}}, T_{\mathrm{ref}}, T_{1}, T_{2}, T_{3}, T_{4}$, and $T_{5}$ temperature distributions for the ALFHS mounted to the CLRDL after INST.

Table 2. Temperature $\left({ }^{\circ} \mathrm{C}\right)$ distribution of specified points for ALFHS mounted to the CLRDL after INST in the steady-state.

\begin{tabular}{ccccccccc}
\hline Time (min.) & $T_{\mathrm{SP}}$ & $\boldsymbol{T}_{\mathrm{j}}$ & $\boldsymbol{T}_{\text {ref }}$ & $\boldsymbol{T}_{\mathbf{1}}$ & $\boldsymbol{T}_{\mathbf{2}}$ & $\boldsymbol{T}_{\mathbf{3}}$ & $\boldsymbol{T}_{\mathbf{4}}$ & $\boldsymbol{T}_{\mathbf{5}}$ \\
\hline 120 & 91.7 & 121.7 & 83.6 & 65.1 & 48.5 & 37.8 & 39.1 & 71.7 \\
\hline
\end{tabular}


Temperature distributions using CUFHS
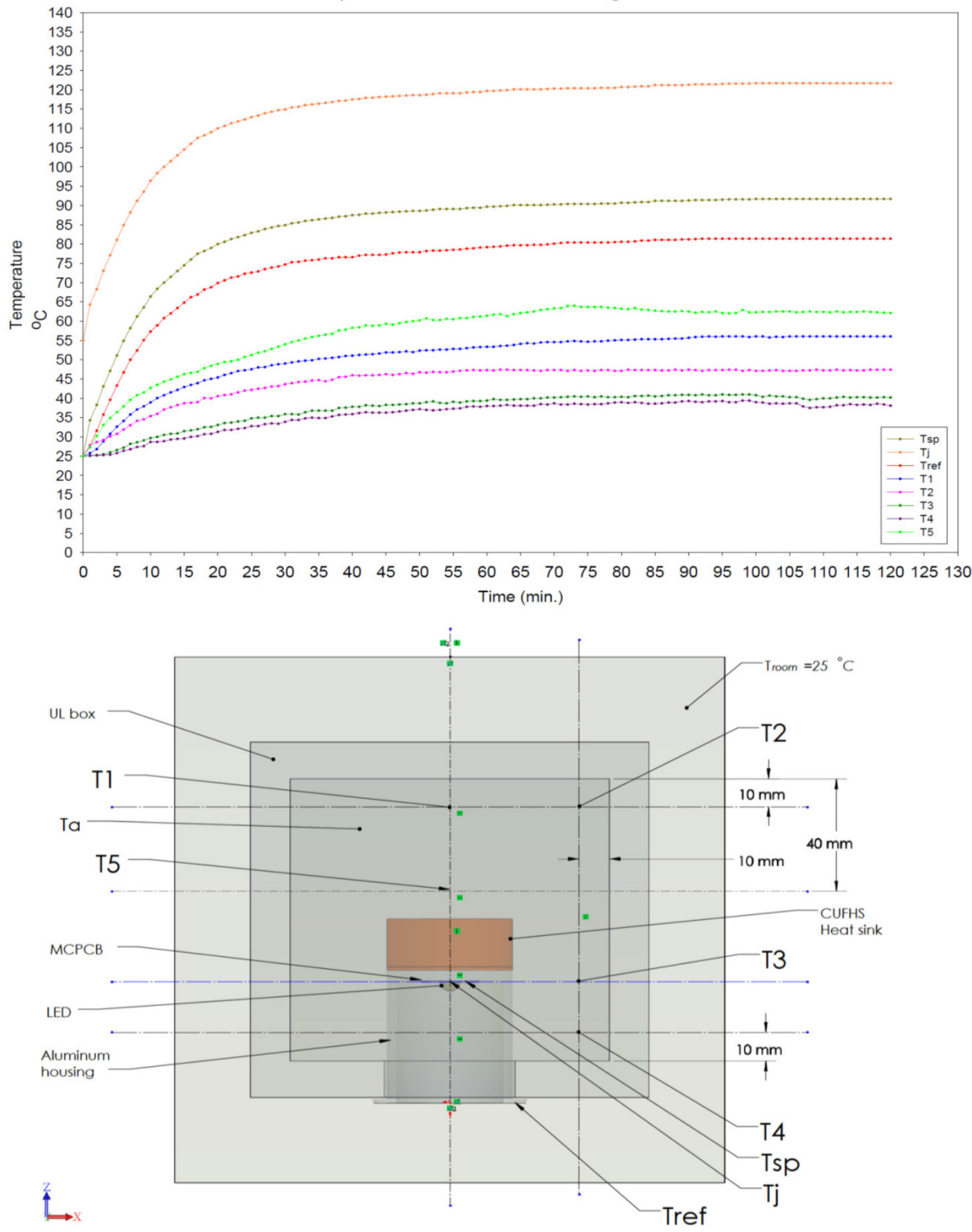

Figure 10. Chart of specified points of $T_{\mathrm{sp}}, T_{\mathrm{j}}, T_{\mathrm{ref}}, T_{1}, T_{2}, T_{3}, T_{4}$, and $T_{5}$ temperature distributions for the CUFHS mounted to the CLRDL after INST.

Table 3. Temperature $\left({ }^{\circ} \mathrm{C}\right)$ distribution of specified points for CUFHS mounted to CLRDL after INST in the steady-state.

\begin{tabular}{ccccccccc}
\hline Time (min) & $\boldsymbol{T}_{\mathbf{s p}}$ & $\boldsymbol{T}_{\mathbf{j}}$ & $\boldsymbol{T}_{\text {ref }}$ & $\boldsymbol{T}_{\mathbf{1}}$ & $\boldsymbol{T}_{\mathbf{2}}$ & $\boldsymbol{T}_{\mathbf{3}}$ & $\boldsymbol{T}_{\mathbf{4}}$ & $\boldsymbol{T}_{\mathbf{5}}$ \\
\hline 120 & 91.7 & 121.7 & 81.4 & 56.1 & 47.4 & 40.2 & 38.1 & 62.1 \\
\hline
\end{tabular}




\section{Conclusions}

The stationary study simulation confirmed the experimental results obtained through testing using J-type thermocouples and a data acquisition system. The LED $T_{\mathrm{sp}}$ values of the CLRDL mounted with the ALFHS and CUFHS were $91.7^{\circ} \mathrm{C}$. This corresponds to the LED junction temperature of $121.7^{\circ} \mathrm{C}$, which is lower than the $135{ }^{\circ} \mathrm{C}$ required by current LED specifications. An accelerated lifetime prediction test indicated that the superior heat sink designs for the CLRDL can withstand high ambient temperatures despite being enclosed in a small space. In addition to the long lifetime, the operating temperature is ensured, as well as a long lumen maintenance time. The two designed heat sinks for the CLRDL ensure a lumen maintenance of more than 25,000 h, complying with the Energy Star requirements for indoor LED lighting fixtures $[17,29,30]$. The numerical simulation and experimental validation indicate that the designed heat sinks resolve the new LED lighting problem.

Acknowledgments: The authors are grateful for the partial support from the project of MOST 105-2812-8-018-001. The authors express their gratitude to Pitotech Co., Ltd., for their technical support. Special thanks is offered to Forcea Cheng.

Author Contributions: Huan-Chu Hsu (Ph. D. student) and Yi-Cheng Huang (Professor) conceived and designed the simulations and experiments; Huan-Chu Hsu and Yi-Cheng Huang performed the numerical simulations and experiments and analyzed the data; Huan-Chu Hsu and Yi-Cheng Huang wrote the paper.

Conflicts of Interest: The authors declare no conflict of interest.

\section{Nomenclature}

T Temperature

$T_{\mathrm{j}} \quad$ Junction temperature

$T_{\mathrm{sp}} \quad$ Solder point temperature

$T_{\mathrm{b}} \quad$ MCPCB temperature

MCPCB Metal core printed circuit board

$T_{\mathrm{h}} \quad$ Aluminum housing temperature

$T_{\mathrm{hs}} \quad$ Heat sink temperature

$T_{\text {box }} \quad$ Test box temperature

$T_{\text {ref }} \quad$ Reference point temperature

$T_{\text {room }} \quad$ Room atmosphere temperature $\left(25^{\circ} \mathrm{C}\right)$

$R_{\text {th }} \quad$ Thermal resistance

$R_{\text {th, j-sp }}$

$R_{\mathrm{th}, \mathrm{sp}-\mathrm{b}}$

$R_{\text {th, b-h }}$

Thermal resistance between junction and solder point

Thermal resistance between solder point and MCPCB

Thermal resistance between MCPCB and aluminum housing

$R_{\text {th, h-hs }}$

$R_{\text {th, hs-box }}$

Thermal resistance between aluminum housing and heat sink

$R_{\text {th, h-ref }}$

$R_{\text {th, sp-ref }}$

A.F.

$E a$

$\mathrm{kb}$

K

$T_{\text {use }}$

$T_{\text {test }}$

e

$\mu$

$u$

$\rho$

I

The specific heat capacity

$F \quad$ The volume force (body force) in any point of the fluid

$\varepsilon_{\mathrm{p}} \quad$ The porosity of the porous material

$\kappa \quad$ The permeability tensor of the porous media 


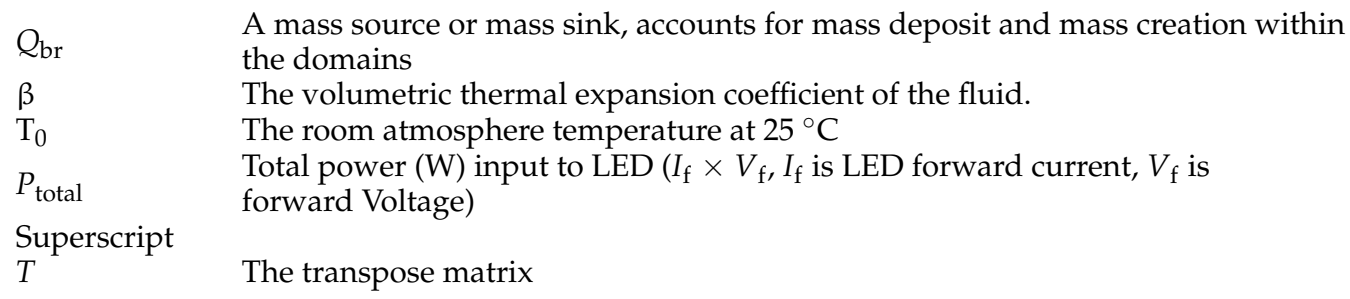

\section{References}

1. Yang, K.; Chung, C.; Tu, C.; Wong, C.; Yang, T.; Lee, M. Thermal spreading resistance characteristics of a high power light emitting diode module. Appl. Ther. Eng. 2014, 70, 361-368. [CrossRef]

2. Tzeng, S.; Jeng, T.; Wang, Y. The cooling Design of a High-Speed Rotating Axis with Ribbed Turbulators. IJETI 2013, 3, 38-48.

3. Sapia, C.; Sozio, G. CFD Transient Model of the Buoyancy Heat Transfer for a Heat Sink: Effects of Geometry Rotation, Thermal Investigations of ICs and Systems (THERMINIC). In Proceedings of the 2012 IEEE 18th International Workshop, Budapest, Hungary, 25-27 September 2012.

4. Chein, R.; Chen, J. Numerical study of the inlet/outlet arrangement effect on microchannel heat sink performance. Int. J. Ther. Sci. 2009, 48, 1627-1638. [CrossRef]

5. Chen, H.; Wang, C. Analytical analysis and experimental verification of trapezoidal fin for assessment of heat sink performance and material saving. Appl. Ther. Eng. 2016, 98, 203-212. [CrossRef]

6. Kushwaha, A.S.; Kirar, R. Comparative study of rectangular, trapezoidal and parabolic shaped finned heat sink. IOSR J. Mech. Civ. Eng. 2013, 5, 1-7. [CrossRef]

7. De Schampheleire, S.; de Jaeger, P.; Reynders, R.; de Kerpel, K.; Ameel, B.; T’Joen, C.; Huisseune, H.; Lecompte, S.; de Paepe, M. Experimental study of buoyancy-driven flow in open-cell aluminium foam heat sinks. Appl. Ther. Eng. 2013, 59, 30-40. [CrossRef]

8. Yao, Y.; Wu, H.; Liu, Z. A new prediction model for the effective thermal conductivity of high porosity open-cell metal foams. Int. J. Ther. Sci. 2015, 97, 56-67. [CrossRef]

9. Chein, R.; Yang, H.; Tsai, T.; Lu, C. Experimental study of heat sink performance using copper foams fabricated by electroforming. Microsyst. Technol. 2010, 16, 1157-1164. [CrossRef]

10. Billiet, M.; de Schampheleire, S.; Huisseune, H.; de Paepe, M. Influence of Orientation and Radiative Heat Transfer on Aluminum Foams in Buoyancy-Induced Convection. Materials 2015, 8, 6792-6805. [CrossRef]

11. Haack, D.P.; Butcher, K.; Kim, T.; Lu, T.J. Novel Lightweight Metal Foam Heat Exchangers. In Proceedings of the 2001 ASME International Mechanical Engineering Congress and Exposition, New York, NY, USA, 11-16 November 2001; pp. 141-147.

12. Hamadouche, A.; Nebbali, R.; Benahmed, H.; Kouidri, A.; Bousri, A. Experimental investigation of convective heat transfer in an open-cell aluminum foams. Exp. Ther. Fluid Sci. 2016, 71, 86-94. [CrossRef]

13. Elayiaraja, P.; Harish, S.; Wilson, L.; Bensely, A.; Lal, D.M. Experimental investigation on pressure drop and heat transfer characteristics of copper metal foam heat sink. Exp. Heat Transf. 2010, 23, 185-195. [CrossRef]

14. Dreeben, T.D.; Betts, D. Simulation and Measurement of Heat Flow in Recessed LED Fixtures Mounted in a UL Box. In Proceedings of the 2014 IEEE Intersociety Conference on Thermal and Thermomechanical Phenomena in Electronic Systems (ITherm), Orlando, FL, USA, 27-30 May 2014.

15. Ahn, B.; Park, J.; Yoo, S.; Kim, J.; Jeong, H.; Leigh, S.; Jang, C. Synergetic Effect between Lighting Efficiency Enhancement and Building Energy Reduction Using Alternative Thermal Operating System of Indoor LED Lighting. Energies 2015, 8, 8736-8748. [CrossRef]

16. Kudsieh, N.; Khizar, M.; Raja, M.Y.A. Thermal modeling of specialty heat-sinks for low-cost COP packaging of high-power LEDs. In Proceedings of the 2012 IEEE 9th International Conference on High Capacity Optical Networks and Enabling Technologies (HONET), Istanbul, Turkey, 12-14 December 2012.

17. Qian, C.; Fan, X.J.; Fan, J.J.; Yuan, C.A.; Zhang, G.Q. An accelerated test method of luminous flux depreciation for LED luminaires and lamps. Reliab. Eng. Syst. Saf. 2016, 147, 84-92. [CrossRef]

18. COMSOL Multiphysics 5.2a; CFD Module, software licensed by COMSOL Inc.; Pitotech: Changhua City, Taiwan, 2016.

19. Chen, Y.; Wang, Z.; Tsai, G. Two-way Fluid-Structure Interaction Simulation of a Micro Horizontal Axis Wind Turbine. IJETI 2015, 5, 33-44. 
20. Maaspuro, M.; Tuominen, A. Thermal analysis of LED spot lighting device operating in external natural or forced heat convection. Microelectr. Reliab. 2013, 53, 428-434. [CrossRef]

21. Kuo, C.H.; Chiou, L.C.; Chen, C.C. Wake flow pattern modified by small control cylinders at low Reynolds number. J. Fluids Struct. 2007, 23, 938-956. [CrossRef]

22. Li, J.; Yang, Q.; Niu, P.; Jin, L.; Meng, B.; Li, Y.; Xiao, Z.; Zhang, X. Analysis of Thermal Field on Integrated LED Light Source Based on COMSOL Multi-physics Finite Element Simulation. Phys. Procedia 2011, 22, 150-156. [CrossRef]

23. Rezaiguia, I.; Kadja, M.; Mebrouk, R.; Belghar, N. Numerical computation of natural convection in an isosceles triangular cavity with a partially active base and filled with a $\mathrm{Cu}$-water nanofluid. Heat Mass Transf. 2013, 49, 1319-1331. [CrossRef]

24. Lee, J.B.; Kim, H.J.; Kim, D. Experimental Study of Natural Convection Cooling of Vertical Cylinders with Inclined Plate Fins. Energies 2016, 9, 391. [CrossRef]

25. Shen, Q.; Sun, D.; Xu, Y.; Jin, T.; Zhao, X.; Zhang, N.; Wu, K.; Huang, Z. Natural convection heat transfer along vertical cylinder heat sinks with longitudinal fins. Int. J. Ther. Sci. 2016, 100, 457-464. [CrossRef]

26. Ye, H.; Gielen, A.W.J.; vanZeijl, H.W.; Werkhoven, R.J.; Zhang, G.Q. Numerical modeling of thermal performance: Natural convection and radiation of solid state lighting. In Proceedings of the IEEE 12th International Conference on Thermal, Mechanical and Multi-Physics Simulation and Experiments in Microelectronics and Microsystems (EuroSimE), Linz, Austria, 18-20 April 2011.

27. Huang, Y.; Chen, X. Investigation of a Ball Screw Feed Drive System Based on Dynamic Modeling for Motion Control. AITI 2017, 2, 29-33.

28. Cai, M.; Yang, D.; Tian, K.; Chen, W.; Chen, X.; Zhang, P.; Fan, X.; Zhang, G. A hybrid prediction method on luminous flux maintenance of high power LED lamps. Appl. Ther. Eng. 2016, 95, 482-490. [CrossRef]

29. ENERGY STAR ${ }^{\circledR}$ Program Requirements Product Specification for Luminaires (Light Fixtures). Available online: https:/ /www.energystar.gov/sites/default/files/asset/document/Luminaires $\% 20 \mathrm{~V} 2 \%$ 200\%20Final.pdf (accessed on 27 September 2016).

30. Koh, S.; Yuan, C.; Sun, B.; Li, B.; Fan, X.; Zhang, G.Q. Product Level Accelerated Lifetime Test for Indoor LED Luminaires. In Proceedings of the 14th International Conference on Thermal, Mechanical and Multi-Physics Simulation and Experiments in Microelectronics and Microsystems, EuroSimE 2013, Wroclaw, Poland, 18-20 April 2011.

(C) 2016 by the authors; licensee MDPI, Basel, Switzerland. This article is an open access article distributed under the terms and conditions of the Creative Commons Attribution (CC-BY) license (http://creativecommons.org/licenses/by/4.0/). 